Men in non-traditional occupations: Career entry, career orientation and experience of role strain

\author{
Ruth Simpson \\ School of Business and Management \\ Brunel University \\ Uxbridge \\ UB8 $3 \mathrm{PH}$ \\ UK \\ Email:r.simpson@brunel.ac.uk
}




\title{
Men in Non-Traditional Occupations: Career Entry, Career Orientation and Experience of Role Strain
}

\begin{abstract}
This paper sets out to explore the experiences of men in non-traditional occupations. In particular it focuses on the dynamics of career entry, career orientation (i.e. preference for intrinsic or extrinsic rewards) and the possible existence, nature and consequences of 'role strain'. Four occupational groups are examined: nurses, cabin crew, librarians and primary school teachers. Results suggest that men fall into three main categories: seekers (who actively chose the 'female' occupation), 'finders' (who did not actively seek a nontraditional career but who found the occupation in the process of making general career decisions) and settlers (who actively chose the occupation, often as a result of dissatisfaction with a more 'masculine' job, and who then settled in their non-traditional career). Settlers in particular are associated with a more intrinsic career orientation and express a desire to remain close to occupational and professional practice. Role strain is prevalent in men's experiences in their non-traditional career. The potential sources of such role strain and the implications for career aspirations and career choices are explored.
\end{abstract}

Key words: careers; non-traditional occupations; gender 


\section{Men in Non-Traditional Occupations: Career Entry, Career Orientation and Experience of Role Strain}

\section{INTRODUCTION}

While research has demonstrated that women pursue male careers because they offer prestige, higher pay and opportunities for advancement (Galbraith, 1992; Chusmir, 1990), little is known about the entry decisions and career orientation of men in non-traditional occupations. The advantages for men in what are generally seen as 'women's jobs' are less clear cut, involving as they do probable sacrifices in terms of pay and status as well as raising questions over their masculinity and suitability for the job (Bradley, 1993; Williams, 1993). Men therefore have less to gain and much to lose by choosing a nontraditional career. Accordingly, despite widespread changes in the occupational structure over the past decade, occupational segregation remains stubbornly intact, forming a potential contributory factor towards gender inequality in the workplace (Williams and Villemez, 1993). For example, in the UK, $85 \%$ of service workers and $79 \%$ of administrative and secretarial staff are women while $92 \%$ of skilled trades, $84 \%$ of machine operatives and $69 \%$ of managers and senior officials are men (EOC, 2003). Only by understanding the career decisions and orientations of male as well as female ‘token' workers, can sex stereotypic work career boundaries be challenged and breached. This paper presents the findings of a research project which has focused on the careers of male workers in four 'non-traditional' occupational groups: nursing, primary school teaching, librarianship and flight attendance (cabin crew). These groups have been identified as being traditionally held by women and as being notable for requiring the 
feminine skills and attributes that society attributes to women e.g. sensitivity, beauty, nurturance and service (Heilman, 2001; Hochschild, 1983).

\section{PREVIOUS RESEARCH}

Various theories, drawing on psychological, social and cultural factors, have emerged to explain occupational choice. Farmer (1995) for example posits three interactive influences: background (e.g. gender, abilities), psychological/personal (e.g. attitudes, beliefs, earlier experiences) and environmental/cultural (e.g. norms, peer pressure, media influences). With a focus on psychological factors, Holland $(1959,1962,1966,1982)$ has highlighted the importance of 'fit' between individual's personality and career choice. This so-called 'trait theory' (Zaccaria, 1970) is based on the assumption that each person is characterised by a unique pattern of capabilities and potentialities (traits) which can be correlated with requirements of specific jobs. The closer the match between traits and requirements, the greater is the likelihood for job satisfaction, success and productivity (Klein and Weiner, 1977). This suggests that the choice of occupation is likely to be an expression of personality and that members of an occupational group are likely to share similar personality characteristics. Medical staff, for example, have been found to be analytical, non-conforming and introspective with strong altruistic motivations (Antony,1998).

Following Holland's model, but with an emphasis on the social as opposed to the psychological self, circumscription and compromise theory sees perceptions of and 
preferences for gender roles as central to occupational choice (Gottfredson, 1981; Gottfredson and Lapan, 1997). Circumscription occurs as young people eliminate occupations as being incompatible with their developing self concepts while compromise occurs as they eliminate their preferred choices through perceptions of inaccessibility (e.g. wrong sex type, low prestige). The theory postulates that gender, as a core element of one's social image, is the first aspect of self concept against which young people judge the desirability of different occupations and that gender is the aspect of self that young people, particularly boys, are least willing to violate when making occupational choices. Therefore, as with trait theories, circumscription and compromise theory emphasises that career choices reflect efforts to implement preferred self concepts and that satisfaction with career choice depends on how well that choice fits or matches that concept.

Other theories which focus on the importance of gender emphasise the effect of socially prescribed gender roles (e.g. Eagly, 1987; Eagly et al, 2000). From this perspective, men choose to enter male dominated occupations (calling for masculine personal qualities) because of gender socialisation processes (e.g. Jacobs, 1989; Wigfield et al, 2000). Such research accordingly suggests gender differences in occupational choice and aspirations. Other studies focus on possible gender similarities and suggest that women's occupational aspirations are becoming more like men's (Farmer and Chung, 1995; Shu and Marini, 1998; Powell, 2002). Powell, for example, found that men and women who saw themselves as possessing an abundance of male characteristics were more likely to aspire to top management positions than those who saw themselves as possessing female characteristics - indicating personality and self concept were significant factors in career 
choice and aspirations rather than gender. However, while some women may be conforming to male patterns, this does not explain the small but growing number of men who choose female roles and female professions.

The more limited literature in this area suggests several factors underlying men's decision to enter non-traditional occupations. Looking at the dynamics of entry into female dominated occupations, Williams and Villemez (1993) differentiated between three broad groups of men: seekers who actively sought female dominated jobs, finders who were looking for other types of work but who ended up in a non-traditional occupation, and leavers who were in 'female' jobs and left them. The typology therefore differentiates between seekers who actively sought this kind of job and finders who did not (the author refers to these situations as 'active' choice and 'passive' choice later in this paper). Findings from Williams and Villemez's study suggest that the majority of men fall into the category of finder. They enter female dominated occupations almost by default in that they were not actively seeking such entry but simply 'fell into it', either through availability of convenience. This suggests that there are analytically important distinctions among men in terms of the dynamics of their entry and also raises the possibility that such considerations may influence subsequent aspirations.

Several reasons have been put forward for men's choice of a non-traditional career. The desire for levels of self fulfilment not available in male sex-typed jobs, greater opportunities for promotion and upward mobility and interaction with the opposite sex are factors suggested by Hayes (1986). Similarly, Chusmir (1992) suggests an interaction 
of personal influences (background, attitudes and values, intrinsic needs), family influences (attitudes towards family roles, relationships with children, marital status) and societal influences (gender role, norms) on men's non-traditional career choice. Research supports the salience of some of these factors. In terms of attitudes and values, while men in non-traditional careers are more likely then women to have leadership aspirations (Williams, 1993), they are also more likely to choose to develop the affective domain of their lives (Schann, 1983; Galbraith, 1992). Altruism and job satisfaction, rather than extrinsic rewards, have been found to be the main motivating factor for male nurses (Smith, 1993; Bartlett et al, 1999). Other personal influences may be age, sexuality and previous occupational history. Chusmir (1992) and Galbraith (1992), for example, found that men in non-traditional careers tended to be older then female counterparts, were more likely to be married and had often sampled other careers while Chung and Harmon (1994) found they were more likely than men in traditional careers to be homosexual. Focussing on the importance of family characteristics, Gutek and Larwood (1987) suggest factors such as attitudes to children and parental occupation as important influences on men's non-traditional career choice.

As Williams and Villemez point out, some men choose to leave their non-traditional occupation and many are denied access, despite having a preference for such a job. Men face limiting factors due to societal and personal barriers that discriminate against free choice (Williams, 1992; Jacobs, 1989). Non-traditional jobs for women offer better pay and opportunities for advancement than gender-typed female jobs. Society understands why women would want a male job because it raises her status and her quality of life. 
Non-traditional jobs for men are likely to be low paid and low prestige. Men's identity as a man may be challenged as well as their sexuality (Mangan, 1994) and their ability to compete in a man's world (Chusmir, 1992; Williams, 1993; Cameron, 2001). Accordingly, some incongruity is likely between gender identity and occupational stereotyping. Role strain theory suggests that role stress and conflicts may act as a barrier to men wishing to enter non-traditional areas of work (Kanter, 1977). However, as Chusmir points out, men in these jobs tend to be less masculine gender typed than men in traditional occupations. They may also work hard to de-emphasise their masculinity (Villeneuve, 1994) and therefore be quite comfortable with their gender role behaviour. Accordingly, they may not experience conflict with their gender a-typical job. This is supported by research by Kuecker (1986) who found that male nurses reported more advantages than disadvantages of their minority position and by Squires (1995) who suggests that male nurses minimise potential gender role conflict by choosing specialities (e.g. mental health, accident and emergency) that are less female gender typed.

Three strands of the above literature are important in terms of understanding the aspirations of men in non-traditional occupations. Firstly, as Williams and Villemez suggest, an understanding of the dynamics of career entry can throw light on subsequent aspirations and goals. Secondly, career orientation (e.g. and emphasis on extrinsic versus intrinsic rewards) has been shown to influence career aspirations (e.g. Powell, 2002; Sturges, 1999) and some variation in career orientation of men in non-traditional occupations has emerged from the work in this area (e.g. Williams, 1993; Smith, 1993; Bartlett et al, 1999). It is therefore important to consider how career orientations for men 
in non-traditional occupations might differ and the likely impact on aspirations and goals. Thirdly, if as Gottfredson suggests, gender is an aspect of self that is least likely to be violated in making a career choice and given the likely incongruity between gender identity and occupational stereotyping for men in 'female' jobs, then the potentiality for 'role strain' may well influence decisions within an occupational context (e.g. choice of occupational specialisms, leadership aspirations, exit decisions). An understanding of the nature and significance of role strain is therefore important in drawing inferences on aspirations and goals of men in 'female' roles.

\section{RESEARCH AIMS AND METHODS}

Against this background, the research project set out to explore the aspirations of men in non-traditional occupations. In particular, from the three key areas outlined above, the project had the following objectives:

- To ascertain the dynamics of men's entry into the non-traditional career (e.g. active choice, passive choice; first career, subsequent career)

- To explore the career orientation of men in non-traditional occupations (e.g. preference for extrinsic or intrinsic rewards) and the extent to which entry dynamics above might influence such an orientation

- To investigate the extent to which men in non-traditional occupations experience 'role strain', the responses to such an effect and how this might impact on career decisions 
The research was based on forty in-depth interviews with male workers from four occupational groups: primary (elementary) school teaching, flight attendance (cabin crew), librarian-ship and nursing. Seven interviews took place with academic librarians, five of whom were at assistant librarian level. All were contacted through a UK based university. Through personal and other contacts, ten primary school teachers from six different schools around London were interviewed. Two were on the senior management team, one was nursery manager and seven were main scale class room teachers. Requests for help with the project were then made through the intranet site of a UK based airline and through a professional nursing journal. In each case this led to other contacts. Accordingly, eight interviews were conducted with cabin crew from three different airlines and with fifteen nurses from six different hospitals in the South-East of the UK. Two of the cabin crew were at more senior purser level. Five nurses were involved in mental health, four in accident and emergency, one in palliative care and the remainder in general nursing.

Interviews were semi-structured, following a set of themes that matched the research questions above. Respondents were asked about their entry decisions (e.g. previous jobs, reasons for any career change, motivating factors for non-traditional career choice), their career orientation (e.g. leadership/professional aspirations, job rewards, sources of satisfaction and dissatisfaction) and possibility and significance of 'role strain'. The latter was captured by asking interviewees to reflect on the attitudes of friends and family to their career choice and their own response to those attitudes; on the reactions of others 
outside their immediate social circle (e.g. when meeting people for the first time in a bar or other similar setting) and their own response to those reactions; and on the stereotypical image of the job and how well this was seen to fit with personal identity. More sensitive topics (e.g. reaction of friends, relationship between masculine and work identities) were explored towards the end of the interview when some rapport had been established. To avoid the danger of appearing over intrusive, specific questions relating to respondents' sexuality were not included in the interview schedule. However, in some cases, respondents volunteered this information, particularly where the orientation was homosexual. In the latter case, some follow-up questions relating to how this might have influenced career decisions were made. Where sexual orientation is pertinent to the analysis, respondents are identified by their sexuality only when this had been clearly stated.

Interviews were tape recorded and analysed using content analysis as discussed by Remenyi (1992), Jankowicz (1991) and Holsti (1968). This is defined as "any technique for making inferences by systematically and objectively identifying special characteristics of messages" (Holsti, 1968, p. 608). On this basis, and with reference to the first two research questions (the dynamics of entry into the non-traditional career; career orientation), career intentions (ie active choice, passive choice), career history (first or subsequent career, nature of previous occupations) and stated career goals (management, professional practice) were used as the 'criteria of selection' (Bruce and Berg, 2001). Subsequent 'clusters' of the above criteria and their frequency across the sample were then identified. 
While the frequency of occurrence of these and other criteria was taken into consideration, so also were their saliency and their relationship to each other. As Ritchie and Spencer (1994) point out, the process of qualitative data analysis is not simply the aggregating of patterns or a reliance on a multiplicity of evidence but additionally includes the weighing up of the salience and dynamics of issues. Accordingly, Bruce and Berg (2001) argue that content analysis can be applied to 'manifest content' i.e. those elements that are physically present and countable as well as to 'latent content' i.e. an interpretive reading of the symbolism underlying the physical data. The researcher therefore interpreted the salience and significance of data, a process referred to as 'deciphering' (Heilman, 1976). For example, with reference to the third research question (the nature and extent of 'role strain'), men were identified as broadly comfortable or as experiencing some discomfort with their non-traditional work role. The researcher then looked beneath this 'frequency' to interpret meanings and identify patterns and themes around the experiences and feelings recounted by men.

\section{RESULTS}

\section{Entry Dynamics}

Three different groups of men, differentiated according to how they entered the nontraditional occupation, were identified from the interview data. These conform in part to Williams and Villemez (1993) categories of 'seekers' (those men who made an 'active 
choice' to enter the non-traditional occupation) and 'finders' (men who made a 'passive choice' in that they did not state a preference for the occupation but found it in the process of making general career decisions) though further differentiating factors beyond Williams and Villemez's analysis were identified (and discussed below). However, a third group emerged from the interviews. Men in this group were identified as 'settlers' in that they had tried a variety of different, often masculine, jobs with limited levels of job satisfaction before settling in their current 'female' occupation. Thirteen men were identified as seekers, nine as finders and eighteen as settlers.

As in Williams and Villemez's study, groups varied with respect to the location of their present job on their scale of preferences. For seekers and settlers, current occupations were high on their preference scale and were 'first best' choices at the time the decision was made. By contrast, the decision to enter a non-traditional occupation was 'second best' for finders and involved some compromise around an alternative and preferred option. Two librarians for example would have preferred an academic career but did not have the necessary credentials. One flight attendant would have preferred a more mainstream post in travel and tourism, but no opportunities presented themselves at the time of the job search. The career decision of finders also had an unplanned element ("I just fell into it" was a typical comment here).

Some variation occurred in career history prior to their entry into a non-traditional occupation. While there was little to distinguish finders from seekers in this respect (for some this was a first career, for others there had been a career change), settlers stand out 
in that the majority had undergone a career change and had moved out of careers that were radically different, in terms of sex type, from their current choice. Consequently, fourteen out of the eighteen men identified as settlers had undergone a career change into their present occupation and for twelve of these, the change was out of a more traditionally 'masculine' area such as engineering, IT, mining, finance, management and the army. Settlers also stand out in that, after periods of dissatisfaction in their previous roles, they generally felt they had found the 'right' occupation.

"I was thrashing around and it just slotted in, it was the right thing at the time" (teacher, ex retail manager)

For some settlers, the career move had involved a sacrifice in terms of career prospects and/or salary.

"I had a good career in my past job and people said you're mad to throw all that away and go and be a student. I knew inside me that I wasn't making a big mistake. I knew and I was determined and against all the odds I said I don't care I'm going to do it anyway and it was probably one of the biggest changes I made in my life history, but I knew it was right and I was determined and I've never ever looked back since that day. ” (nurse, ex manager of an agricultural company) Some diversity, therefore, was found in terms of the entry dynamics of men into a nontraditional career. The three groups identified were characterized by differences in career entry intention and by the location of their non-traditional career in their scale of job preferences. Further features concerned the existence and nature of career change into the non-traditional occupation and accompanying feelings of self realisation. 


\section{Career orientation}

Interviews explored the extent to which men gave priority to extrinsic rewards (e.g. pay, career progression) and/or intrinsic rewards (e.g. self fulfillment, job satisfaction). Not surprisingly, given the low pay associated with the four occupational groups, pay on its own was not a high priority. Nevertheless, a desire to climb the pay scales as quickly as possible was a motivating factor behind career progression goals for some men. Out of the 40 men interviewed, fourteen had ambitions to reach senior positions and on this basis could be seen to have some extrinsic career orientation. The largest group (21 in total) comprised of men who had no such ambitions and were happy to remain at their present level. The remaining five had long term plans to leave the occupation.

Some variation in career orientation emerged by entry category (seekers, finders, settlers). While there is no discernible pattern between seekers and finders, settlers gave priority to intrinsic rather than extrinsic rewards. Thirteen out of the eighteen settlers identified claimed a preference for remaining close to professional and occupational practice rather than moving into management. The following quotes give evidence to this trend:

"I'm not interested (in promotion)..I just want to be a good class room teacher"

As we have seen, settlers often contrasted the level and nature of job satisfaction in their current job with feelings of dissatisfaction in previous careers. One ex-army professional who had also worked as a croupier, car salesman and IT consultant commented after 
entering the teaching profession: "I never looked back". Other men reflected on the enjoyment experienced and satisfaction gained in their new career:

"I was doing my PhD and then I wanted something that was completely easy going, variety where I could use my languages. It was the social contact, the interaction with people, the lack of routine" (cabin crew, ex teacher)

“I worked in industry and I didn't enjoy it because I didn't enjoy being sat at a desk all day -and I knew that what I really wanted to do was be a teacher. It's incredibly rewarding. What makes it great is ..the respect you have or the relationship you build up especially with a class for a year, the depth of relationship you have is good" (teacher, ex insurance officer)

Overall, while a sizeable group expressed a desire to move into management or leadership positions, most men claimed little interest in ascending the hierarchy and held a more 'intrinsic' career orientation. Some differentiation emerged by entry dynamic with settlers preferring to remain close to professional practice and giving greater weight to intrinsic rewards.

\section{Role Strain}

Role strain has the potential to influence aspirations, for example through choice of occupational specialisms, leadership goals and /or career exit decisions. Discomfort with gender role behavior may arise if tensions exist between gender identity and occupational stereotyping. For men in non-traditional occupations, therefore, conflicts can occur 
between the need to maintain masculine identities and feminine associations and/or demands of the job. Accordingly, interviews explored any potential conflict between masculine and work identity, the reaction of friends, family and peers to their nontraditional career choice and, in each case, their own response. In this context, embarrassment, discomfort and shame were common themes expressed by men from across the sample - though a smaller group, of mainly homosexual men, claimed to feel no discomfort in this respect. In this context, 22 men expressed some discomfort with their non-traditional role while twelve men claimed to have no problems in this respect (the remaining six men either appeared reluctant to pursue this line of enquiry or made ambiguous claims). Out of the twelve men claiming no discomfort in their non-traditional role, nine had stated in the course of interviews that they were homosexual.

Some variation emerged in the source of discomfort. In some cases, these feelings were located 'internally' in men's own sense of self and self worth. As one librarian commented, "I don't fully respect myself in this work". Other men expressed similar feelings which related to their perceptions of self:

I find it embarrassing..there is part of me that does believe, and it's a terrible thing to say, but there is part of me that believes that it is a woman's job-and that embarrasses me . (primary school teacher)

I still carry a bit of shame about being a nurse in a way, because I consider it to be slightly women's work. (nurse) 
I don't feel comfortable and I'm embarrassed that I'm in this business and I wish I could get out and I think a lot of men, they feel the same. (cabin crew)

It wasn't a problem for anyone else but me, but for me having worked in quite a sort of rough and ready area with drug users around quite tough issues, then to be working with a group of middle class women..it wasn't me. (nurse, ex youth worker)

The last three quotes were from men who felt so uncomfortable in their work roles that they were taking active steps to leave and move into alternative careers.

In other cases, feelings of embarrassment or discomfort were located 'externally' in that they emanated from how they were perceived by others (there was some overlap between the two. In this context, men were often sensitive to the judgements of friends and peers (families were largely supportive of men's career choice). Male friends and acquaintances were seen as less accepting than female peers of their non-traditional career choice. Such gender role violation triggered disapproval and ridicule:

"The women find it fascinating - but the men, straight men they're like OK, whatever, let's not discuss that any further because they immediately think I'm talking to a woofter!" (teacher)

"I do get a bit of Mickey - like people say it's a sad, boring job: (librarian) 
“People laugh and say he's a primary school teacher, and it does get into to you so I suppose that does effect how you deal with other people and who you mix with" (teacher)

Stigma was a common term used to describe the reactions of others towards their nontraditional role. This stigma was usually associated with assumptions of homosexuality and of sexual perversion. As one primary school teacher commented: Because I am a man in early years I'm aware that I am a freak and that I' $m$ weird and in the wrong job. Most men claimed that they "were not bothered" or had "grown used to" such negative stereotyping - though the ability to resist gender role expectations was not necessarily characteristic of their 'younger selves' as the following quotes suggest:

If you had have asked me when I left school if I wanted to be a male nurse I certainly would have shunned it and most of my class mates would have run me out of town really... it was considered to be a gay profession. (nurse)

I suppose things like being misjudged, mislabelled... male nurses being gay. I think probably at 16 years old I didn't have shoulders broad enough to have carried that weight, now it doesn't matter one iota. (nurse)

Men had various strategies which helped to minimize the potential for negative stereotyping and so helped to reduce potential role strain and overcome associated discomfort with the image of the job. This involved the manipulation of meanings around the non-traditional role. One strategy was to give out minimal or skewed information. For example one cabin crew stated that he worked in tourism, a teacher deliberately omitted 
the word 'primary' so his audience might assume he was in (higher status) secondary education, a cancer nurse said he worked for a cancer charity, a business school librarian only offered the information that he worked for a university. One cabin crew commented: I belong to a swim team now and I don't want them to think ...I say I work at (airline) but I don't tell them what I do, if they ask I don't lie, but then I tell them I'm looking for another job. (cabin crew)

Well I'm not ashamed of it but it's one of these things I don't like going around and telling people, if people ask me about it I'll talk about it, but if they don't ask me about it I'm not going to go and say oh I'm a nurse. (nurse)

A second strategy was to emphasis the masculine components of the job. Teachers often focused on the sports side of their work (all but one had an involvement in this capacity) and the importance they put on managing the football and cricket teams and nine of the fifteen nurses interviewed had chosen more masculine specialisms of mental health (historically a masculine occupation) and accident and emergency (seen as more exciting and demanding than general nursing). Mental health, for example, was seen to require more 'masculine' skills. One mental health nurse commented:

I think a lot of males come into mental health nursing because there is more pay we are on a different scale, well we get psychiatric leave and danger money if you work with mentally ill people, because there is a risk of aggression or violence. You need to be quite tough here. (nurse) 
Role strain therefore emerged as a common feature for men in non-traditional roles. Not all men, however, claimed they experienced discomfort in this way. For some, mainly homosexual men, the non-traditional career fitted well with their sense of self. Sexuality was therefore an important contributory factor to how comfortable men felt with the job. Twelve of the 40 men interviewed professed to be homosexual and many of these admitted that their choice of occupation was influenced by their sexuality.

"I did go into it because I could relax and be myself" (cabin crew)

"The masculine side of me is there all the time - but I also have a deep level of nourishing that makes me able to empathize, like hold their hands and put patients' minds at rest - rather than sitting like a truck driver by the side of the bed" (nurse)

"It makes the world of difference - the very fact that I can sit there and share moisturizing tips with the girls and it really doesn't matter to me, if people think I'm gay then yes they're right, well done. It fits in perfectly, absolutely”. (nurse)

You've got the girls and they're like oh I love you. So they're all embracing, if anything you find complete acceptance which is what I found in this job, I have found complete and utter acceptance (cabin crew).

Overall, while homosexual men tended to experience a degree of comfort in their nontraditional role, some role strain (in the form of feelings of discomfort, embarrassment or shame) was common for the majority of men. For some, these feelings were internally 
located in that they reflected how men felt about themselves. For others, feelings were externally located in that they reflected how they were perceived by others. In this latter respect, the judgments of male friends and peers were particularly pertinent. Men adopted a variety of strategies to minimize expressions of disapproval. These included giving out minimal or skewed information, placing emphasis on more masculine components of the job and opting for specialisms which are associated with more masculine skills and competencies. A few men had decided to leave the non-traditional occupation.

\section{DISCUSSION}

This paper set out to explore the experiences of men in non-traditional occupations. In particular it focused on the dynamics of career entry, career orientation and the possible existence, nature and consequences of role strain. Such research is important given the feminization of local labour markets and the need to challenge occupational segregation if progress is to be made in reducing inequality at work.

Results suggest that men in non-traditional occupations fall into three main categories. These categories conform in part to Williams and Villemez's (1993) typology of seekers and finders. Accordingly, seekers made 'active choices' by actively seeking a nontraditional career while finders made 'passive choices' in that they 'found' the occupation either through a process of compromise, as discussed by Gottfredson (1981), or because of availability and convenience. However, as we have seen, additional factors have been identified to distinguish between the two categories and to establish a third category of 'settlers' i.e. men who, after a career change out of a mainly 'masculine' occupation, actively seek and settle into the non-traditional career. These factors include the location 
of the current occupation in respondents' scale of preferences, whether the occupation comprises a first or subsequent career, the nature of any previous occupation and relative levels of satisfaction compared to that job.

This typology throws new light on various issues relating to men's aspirations within a non-traditional career. Contrary to predictions concerning the ambitious work attitude among men in such occupations (e.g. Squires, 1995; Evans, 1997; Isaacs and Poole, 1996; Williams, 1993), the majority of men in this study had limited goals in terms of attaining management or leadership positions. This is particularly the case for settlers, who stand out in that they are more likely than the other two groups to have a preference for remaining close to professional practice. One possibility here is that settlers, having transferred from a more masculine role, may well be rejecting the male career progression model of steady increases in status and power. In nursing for example, while some evidence suggests men move up the career ladder at a faster pace than women (e.g. Equal Opportunities Review, 1998), other work (e.g. Kemp, 1988) has found that many men were reluctant to be removed away from clinical practice and so did not aspire to management roles. Therefore the notion of 'fast track' or 'straight through' careers, where upward mobility is facilitated by assumptions of leadership capabilities associated with the masculine gender (Williams, 1993), may not be representative for all men.

This suggests a more 'intrinsic' career orientation for men in non-traditional occupations. As Schann (1983) and Chusmir (1992) argue, men in non-traditional roles may be seeking to develop the affective domain of their lives and may therefore possess lower 
levels of status needs. Studies of male nurses, for example, have found that job satisfaction is the most important factor influencing men's commitment to the profession (Smith, 1993; Bartlett et al, 2001). Settlers in particular place a high priority on self fulfillment and job satisfaction. This is often in contrast to dissatisfaction with previous 'masculine' careers with their strong associations with extrinsic rewards and status attainment.

A further issue concerns the significance of self concept to the process of occupational choice. As Holland (1959, 1962, 1966, 1982) suggests, a sense of 'fit' between self and the job is an important explanation for aspirations and for Gottfredson (1981), these aspirations are largely dependent on gender. As Pringle (1995) points out, in the context of men in non-traditional roles, a lack of fit or 'role strain' can emanate from assumptions of homosexuality or from feminine associations. Results from this study attest to the salience of 'fit' in career aspirations and choices as well as to the high potential for role strain or discomfort between the 'masculine self' and work identity. Evidence also suggests that where negative stereotyping is to some extent 'internalized' (in that it appears to impact on self perceptions), decisions to exit the occupation are more likely. More frequently, however, the source of 'role strain' was seen as external i.e. located more in the perceptions of others and seen to have less impact on the sense of self. In this situation, various strategies to reduce such role strain were in evidence. These included giving out minimal or skewed information, placing emphasis on more masculine components of the job and opting for specialisms which are less stereotypically female. Similar strategies have emerged from other studies of men in non-traditional occupations. Nurses for example have been found to cluster in specialist areas which are perceived as 
more 'masculine' (e.g. Kuecker, 1985; Wilshaw, 1987; Egeland and Brown, 1989). Other studies of men in non-traditional occupations (e.g. Lupton, 1999; Williams, 1993; Cross and Bagilhole, 2000) have found that fears of feminisation and stigmatisation have been associated with attempts to reconstruct the job to minimize its non-masculine associations.

Such strategies suggest a tension for men in non traditional roles between the 'feminine' nature of the job and dominant discourses of (hegemonic) masculinity. Such discourses have a crucial role to play in promoting and sustaining the sexual division of labour and the social definition of tasks as either 'men's work' or 'women's work'. As Morgan (1992) suggests, notions of work are central to masculine identities and organizations exist as major sites for the construction and reconstruction of 'what it means to be a man'. This has consequences for those men who move into gender a-typical areas and who thereby challenge conventionally held attitudes and assumptions concerning 'masculine work'. Reports of a less accepting attitude towards men's non-traditional career choice on the part of male peers may also point to a greater investment by men in gender conformity. This view is supported by Kimmel (1994) who argues that it is men rather than women who scrutinize other men for signs of femininity and homosexuality and who act as the 'gatekeepers' of the hegemonic ideal. Overall, the prevalence of 'role strain' in this and other work points to the strength and potency of masculine discourses, and while gender conformity strategies may help to minimize such role strain, some conflict between gender and work role is a common experience for men in non-traditional careers 
Finally, the importance of fit between self and the job is supported by work on sex role orientation (e.g. Chung and Harmon, 1994; Jones and Lamke, 1985; Hodgins and Kalin, 1985; Jackson, 1983; Jome and Tokar, 1998; Luhaorg and Zivian, 1995) which emphasises the significance of congruence between individual's sex role orientation and the sex type of the occupation. A non-traditional sex role orientation is therefore likely to be associated with a non-traditional career choice so that men in non-traditional jobs may tend to be less 'masculine' gender typed than men in traditional occupations (Chusmir, 1990). As Chung and Harmon (1994) and Jones and Lamke (1985) suggest, homosexual men are more likely than heterosexual counterparts to have non-traditional career preferences and are more likely to exhibit a non-traditional sex role orientation. The relatively high proportion of men from the sample who attested to a homosexual status, together with the low levels of role strain among this group, gives some credence to significance of the relationship between sex role orientation and occupational sex type.

\section{Conclusion}

This paper has made a significant contribution to the general literature on gender and organization and, more particularly, to our understanding of the career choice and aspirations of men in non-traditional occupations in the following ways. Firstly, the typology of seekers, finders and settlers throws light on the dynamics of career entry and the subsequent impact on career aspirations. As such, it constitutes a useful frame for further work. Secondly, the research highlights the prevalence of role strain as well as its significance for career decisions around occupational specialisms, specialist activities 
and, in some cases, exit from the job. Building on this, future research might help establish the extent to which potential role strain might act as a barrier to men at earlier, pre-entry stages in their career. Finally, the research has highlighted inherent tensions and ambiguities for men in non-traditional roles as they manage conflict between the effects of negative stereotyping on the one hand and high levels of job satisfaction and self fulfilment on the other. Similarly and relatedly, men work to manage conflict between dominant notions of masculinity and the 'feminine' nature of their job. The greater levels of harmony experienced by many homosexual men may serve to highlight these tensions within the heterosexual context.

\section{Limitations and Future Research}

This study has several limitations. Firstly, the method of sampling may well have compromised the reliability of some of the data. Men who respond to an appeal on an intranet site or in a professional journal may be more positive about their job than other men who may not have felt motivated to offer themselves for interview. This may have led to more positive outlooks on career choice than would otherwise have been the case. A second methodological problem concerns the gender difference between interviewer (female) and interviewee (male). This may have led to a reluctance, on the part of men, to discuss gender sensitive issues. However, all the men interviewed spent a large amount of their working day with women and were therefore used to communicating with women on different levels. Certainly, when this issue was raised with one interviewee, the response was that he would feel more constrained (and threatened) talking to a man. Finally, the research is based on just four occupational groups. Further research on other 
groups and in different organizational settings may help establish the extent to which the findings from this research can apply in a more general context. 


\section{REFERENCES}

Antony, J. (1998). Personality career fit and freshman medical career aspirations: A test of Holland's theory, Research in Higher Education. 39, 6, 679-698

Bartlett, P. Hind, R. and Taylor, W. (1999) A comparison of the career aspirations of degree and P2000 diploma graduates from UK nursing programmes, Journal of Nursing Management, 7, 37-43

Bradley, H. (1993). Across the Great Divide: The Entry of men into Women's Jobs, in C. Williams (ed) Doing Women's Work: Men in Non-Traditional Occupations, (pp10-28). London: Sage

Bruce, L. and Berg, M. (2001). Qualitative research methods for the social sciences, Needham Heights, MA: Allyn and Bacon

Cameron, C. (2001). Promise or Problem? A Review of the Literature of Men Working in Early Childhood Services, Gender Work and Organization, 8, 4, 430-453

Chung, Y. and Harmon, L. (1994) The Career Interests and Aspirations of Gay Men: How Sex-Role orientation is Related, Journal of Vocational Behaviour, 45, 223-239

Chusmir, L. (1992) Men who Make Non-traditional Career Choices, Journal of Counselling and Development, 69, 11-15

Charmez, K. (1983) A Grounded Theory Methodology in Contemporary Field Research: a Collection of Readings. In R.M. Emerson (ed). Boston:Little Brown

Cross, S. and Bagilhole, B. (2000). Girl's Jobs for the Boys? Men, Masculinity and Nontraditional Occupations. Gender Work and Organization, 9/2, 204-226

Eagly, A. (1987) Sex Differences in Social Behaviour: A Social Role Interpretation, Erlbaum, Hillsdale, NJ

Eagly, A., Wood, W. and Diekman, A. (2000) Social Role Theory of Sex Differences and Similarities: A Current Appraisal. In Eckes, T. and Trautner, H. (eds) The Developmental Social Psychology of Gender, Erlbaum, Mahwah, NJ 363-390

Egeland, J. and Brown, J. (1989). Men in Nursing: Their Field of Employment, Preferred Fields of Practice and Role Strain, Health Service Research, 24, 693-707

EOC (2003) Facts about Men and Women in Great Britain, Equal Opportunities Commission, UK: Manchester

Equal Opportunities Review (1998) No 79 May/June, p 7-8 
Evans, J. (1997) Men in Nursing: Exploring the Male Nurse Experience, Nursing Inquiry, $4,142-145$

Farmer, H. (1985). Model of Career Achievement Orientation for Men and Women, Journal of Counselling Psychology, 32, 363-390

Farmer, H. 1997 Women's Motivation Related to Mastery, Career Salience and Career Aspiration: a Multivariate Model Focusing on the Effects of Sex Role Socialisation, Journal of Career Assessment, 5, 355-381

Farmer, H. and Chung, Y. (1995). Variables Related to Career Commitment, Mastery, Motivation and Level of Career Aspiration among College Students, Journal of Career Development, 21, 4, 265-278

Galbraith, M. (1991) Attracting Men to Nursing: What will they find important in their Career, Journal of Nursing Education, 30, 182-186

Galbraith, M. (1992) Understanding the Career Choices of Men in Elementary Education, Journal of Educational Research. 85, 4, 246-253

Gottfredson, L. and Lapan, R. (1997). Assessing Gender Based Circumscription of Occupational Aspirations, Journal of Career Assessment, 5, 4, 419-441

Gottfredson, L. (1981). Circumscription and Compromise: A Developmental Theory of Occupational Aspirations, Journal of Counselling Psychology, 28, 545-579

Gutek, B. and Larwood, L. (1987). Working towards a Theory of Women's Career Development. In B. Gutek and L. Larwood (eds) Women's Career Development, Newbury Park, CA: Sage

Hayes, R. (1986). Men's Decisions to Enter or Avoid Non-traditional Occupations, The Career Development Quarterly, 35, 2,, 89-101

Hayes, R. (1989). Men in Female Concentrated Occupations, Journal of Organizational Behaviour, 10, 210-212

Heilman, M. (2001) Description and Prescription: How Gender Stereotypes Prevent Women's Ascent up the Organizational Ladder, Journal of Social Issues. 57, 657-674

Heilman, S. (1976). Synagogue life: a study in symbolic interaction. Englewood Cliffs, NJ: Prentice Hall

Hochschild, A. (1983). The Managed Heart: Commercialisation of Feeling. University of California Press, Berkeley 
Hodgins, D. and Kalin, R. (1985) Reducing Sex Bias in Judgements of Occupational Suitability by the Provision of Sex-typed Personality Information, Canadian Journal of Behavioural Science, 17, 346-358

Holland, J. (1959). A Theory of Vocational Choice, Journal of Counselling Psychology, $6,35-45$

Holland, J. (1962). Some Explorations of a Theory of Vocational Choice, Psychologial Monographs, 76, 26, 1-545

Holland, J. (1966) The Psychology of Vocational Choice, Waltham, MA Blaisdell

Holland, J. (1982) The SDS helps both Females and Males: A Comment, Vocational Guidance Quarterly, 30, 3, 195-197

Holsti. O. (1968). Content Analysis. In G. Lindzey \& E.Aaronsfield (Eds.), The Handbook of Social Psychology. Reading, MA: Addison Wesley

Isaacs, D. and Poole, M. (1996) Becoming a Man and Becoming a Nurse: Three Men's Stories, Journal of Gender Studies, 5,1, 3-47

Jackson, L. (1983) Gender, Physical Attractiveness and Sex Role in Occupational Treatment Discrimination: The influence of Trait and Role Assumptions, Journal of Applied Social Psychology, 13,5, 443-458

Jacobs, J. (1989) Revolving Doors: Sex Segregation and Women's Careers, Stanford University Press, Stanford, CA

Jankowicz, A. 1991. Business research projects for students. London:Chapman and Hall

Jones, S. and Lamke, L. (1985). The Relationship between Sex -role Orientation, Selfesteem and Sex-typed Occupational Choice of College Women, Psychology of Women Quarterly, 9,1, 145-152

Jome, L. and Tokar, D. (1998). Dimensions of Masculinity and Major Choice Traditionality, Journal of Vocational Behaviour, 52,120-134

Kanter, R. (1977) Some Effects of Proportions on Group Life: Skewed Sex Ratios and Responses to Token Women, American Journal of Sociology, 82, 965-990

Kemp, J. (1988). Graduates in Nursing,: A Longitudinal Study at the University of Hull, Journal of Advanced Nursing, 13, 282-287 
Kimmel, M. (1994) Masculinity as Homophobia: Fear Shame and Silence in the Construction of Gender Identity in H. Brod and M. Kaufman (eds) Theorising Masculinities, London: Sage

Klein, K. and Weiner, Y. (1977). Interest Congruency as a Moderator of Relationship between Job Tenure and Job Satisfaction and Mental Health. Journal of Vocational Behaviour, 19, 91-98

Kuecker, L.(1986). Men in Nursing, Dissertations Abstracts International, 47,1, 318

Luhaorg, H. and Zivian, M. (1995). Gender Role Conflict: The Interaction of Gender, Gender Role and Occupation, Sex Roles, 33 (9/10), 607-620

Lupton, B. (1999). Maintaining Masculinity: Men who do Women's Work, British Journal of Management, 11, S33-48

Mangan, P. (1994). Private Lives, Nursing Times, 90,14, 60

Morgan, D. (1992) Discovering Men, London: Routledge

Powell, G. (2002) Gender, Gender Identity and Aspirations to Top Management, paper presented at the British Academy of Management Conference, London. Sept.

Pringle, K. (1995). Men, Masculinities and Social Welfare, London: UCL Press

Remenyi, D. (1992). Researching information systems: data analysis methodology using content and correspondence analysis, Journal of Information Technology, 7, 2, 75-90

Ritchie, J. and Spencer, L. (1996) Qualitative Data Analysis for Applied Policy Research in A. Bryman and R. Burgess (eds) Analysing Qualitative Data, London: Routledge

Schann, M. (1983). Career Plans of Men and Women in Gender Dominant Professions, Journal of Vocational Behaviour 22, 343-356

Schoon, I. and Parsons, S. (2002) Teenage Aspirations for Future Careers and Occupational Outcomes, Journal of Vocational Behaviour, 60, 262-288

Shu, X. and Marini, M. (1998). Gender Related Change in Occupational Aspirations, Sociology of Education, 71, 44-68

Smith, L. (1993). A Follow up Study of the Bachelor of Nursing Graduates 1982-1990, University of Glasgow, Scotland, Journal of Advanced Nursing, 18, 1840-1848

Squires, T. (1995). Men in Nursing, RN 199558 (7), 26-28 
Sturges, J. (1999). What it means to succeed: personal conceptions of career success held by male and female managers at different ages. British Journal of Management, 10, 239-252

Villeneuve, M. (1994). Recruiting and Retaining Men in Nursing: A Review of the Literature, Journal of Professional Nursing, 10, 4, 217-228

Wigfield, A., Battle, A., Keller, L. and Eccles, J. (2002). Sex Differences in Motivation, Self Concept, Career Aspiration and Career Choice: Implications for Cognitive Development in McGillicuddy-De Lisi, A. and De-Lisi, R. (eds) Biology, Society and Behaviour: The Development of Sex Differences in Cognition, Ablex, Westport, CT: 93124

Williams, C. (1993). Doing Women's Work: Men in Non-Traditional Occupations, London: Sage

Williams, C. (1992) The Glass Escalator: Hidden Advantages for Men in the 'female' professions. Social Problems, 39, 253-267

Williams, L. and Villemez, W. (1993). Seeker and Finders: Male Entry and Exit in Female Dominated Jobs, in C. Williams (ed) Doing Women's Work: Men in NonTraditional Occupations, London: Sage

Wilshaw, G, (1987). Male Models, Nursing Times, 83, 70 (March, 1987)

Zaccaria, J. (1970). Theories of Occupational Choice and Vocational Development Boston, MA: Houghton Mifflin Company 